\title{
Energy and resilience: The effects of endogenous interdependencies on trade network formation across space among major Japanese firms
}

\author{
PETR MATOUS \\ School of Engineering, Department of Civil Engineering, University of Tokyo, Tokyo, Japan \\ and \\ Complex Systems Research Group, Faculty of Engineering and IT, The University of Sydney, \\ New South Wales 2006, Australia \\ (e-mail: petr.matous@sydney.edu.au) \\ YASUYUKI TODO \\ Graduate School of Economics, RIETI and Waseda University, 1-6-1 Nishi-Waseda, Shinjuku-ku, \\ Tokyo 169-0051, Japan \\ (e-mail: yastodo@waseda.jp)
}

\begin{abstract}
The dynamic drivers of interfirm interactions across space have rarely been explored in the context of disaster recovery; therefore, the mechanism through which shocks propagate is unclear. This paper uses stochastic actor-oriented modeling to examine how trade networks among the 500 largest Japanese companies evolved during 2010 and 2011, i.e. before and after the Great East Japan Earthquake to identify sources of vulnerability in the system. In contrast to previous reports on broken supply chains, the network displayed only modest change even in the directly affected areas. Controlling for distance and for firm size, we find that when firms changed their partners, they preferred firms that were popular among other firms, that had partners in common with them and that also bought some products or services from them. These findings concur with a criticism that Japanese firms avoid external actors and exhibit inflexibility in reorganizing their networks in times of need, which contrasts with the non-cliquish network structures observed in high-performing economic sectors. The results also highlight the role of energy firms in disaster resilience. Unlike other large Japanese companies that cluster in major urban centers, energy firms are distributed across Japan. However, despite their peripheral physical locations, energy firms are centrally located in trade networks. Thus, while a disaster in any region may affect some energy firms and lead to large-scale temporary shocks, the entire network is unlikely to be disconnected by any region-specific disaster because of the spatial distribution of the topological network core formed by energy companies.
\end{abstract}

Keywords: interfirm networks, network evolution, geography, stochastic actor-oriented models, disaster resilience, Japan

\section{Introduction}

In March 2011, Japan was struck by an earthquake that has come to be known as the Great East Japan Earthquake. In the days following the disaster, electricity and 
supply shortages - even in regions that were distant from physically damaged areas of the country - highlighted the interconnectedness and vulnerability of the Japanese economy (Carvalho et al., 2014). The aftermath of the disaster demonstrated the importance of interfirm networks for disaster resilience and recovery when disruptions spread and support is exchanged among business partners across a disaster-stricken country (Sato, 2012; Todo et al., 2014; Tokui et al., 2012).

Understanding the mechanism of interfirm network formation is crucial to identifying potential sources of vulnerability to disasters and pathways for national economic revival because the nature of inter-agent micro interactions determines how systemic shocks propagate through the underlying networks and translate into macro-economic shocks (Acemoglu et al., 2015). For example, strong tendencies toward trading in geographically concentrated cliques, which may be a sign of traditional Japanese "keiretsu" business networks (Lincoln \& Gerlach, 2004), may affect an entire system's resilience to region-specific shocks. New modeling methods have made it possible both to uncover previously neglected endogenous network mechanisms through which economic structures emerge and to test various firm management strategies across industries regarding their tendencies to concentrate or diversify economic interactions across groups of firms and/or space.

It is most important to elucidate these tendencies for the main actors in an economy because a small number of companies may have a disproportionately large influence over the economy of an entire nation (Aoyama et al., 2010; Gabaix, 2011). For example, the top five Japanese firms account for one-fifth of Japanese exports (Canals et al., 2007). Thus, the failure of such prominent nodes critically impairs the connectivity of the entire network (Albert et al., 2000), whereas their successes can yield positive effects for the entire country (Canals et al., 2007; Gabaix, 2011).

To explain how systemic shocks propagate across the country, this paper examines the networking tendencies of the major economic actors in terms of topology and geography. Specifically, it investigates endogenous network interdependencies that played important roles in reforming trade structures among the 500 largest Japanese firms during the one-year period around the Great East Japan Earthquake. Special attention is paid to energy companies and the geography of their links which have been identified as occupying an important position in the spatially embedded networks of the major economic actors in Japan.

\section{Theoretical framework}

\subsection{Industrial agglomeration and economic interactions across space}

As a result of the rapid development of communication technologies and the accompanying changes in how companies manage their operations, bestselling authors predicted the "the death of distance" and suggested that the world would become "flat." (Cairncross, 2001; Friedman, 2005). In this new world, firms were expected to interact regardless of their location. However, numerous studies conducted globally have repeatedly reaffirmed that geography remains important to many types of social and economic interactions (Caplow \& Forman, 1950; Carrasco \& Miller, 2006; 2008; Carrasco et al., 2008a ; Carrasco et al., 2008b; Daraganova et al., 2012; 
Duranton \& Overman, 2005; Gonzalez et al., 2008; Greenbaum \& Greenbaum, 1985; Hipp \& Perrin, 2009; Koskinen \& Lomi, 2013; Matous et al., 2013; Nakajima et al., 2012; Onnela et al., 2011; Preciado et al., 2012; Schaefer, 2012; Song et al., 2010; van der Berg et al., 2010; Wellman \& Tindall, 1992). The world has not become flat, and the tendency of economic actors to agglomerate in space have not diminished (Fujita \& Thisse, 2013).

The spatial agglomeration of firms may be threefold and yield the following major benefits (Duranton \& Puga, 2004; Hoover, 1937; Marshall, 1920): (1) availability of specialized intermediate goods, (2) pooling of specialized labor, and (3) information spillovers. The second and third factors are not directly related to supply networks. Thus, if major Japanese firms agglomerate mainly for better access to specialized labor and information, the number of partners located at short distances may not be particularly high compared with the number of large firm headquarters concentrated in urban centers. In such a case, geographic distance may not be a significant predictor of the creation or dissolution of network ties after accounting for the highly concentrated spatial distribution of major firms in Japan.

However, the first potential reason for agglomeration, i.e. proximity to suppliers, is directly related to the formation of trading networks and may confound endogenous dynamic network mechanisms. Therefore, in the present study, we control for the possible effects of physical distance to examine network interdependencies among the trading links described below.

\subsection{Endogenous network formation}

The effects of the Great East Japan Earthquake on firms' revenues and their supply chains have previously been examined (Sato, 2012; Todo et al., 2014; Tokui et al., 2012). As discussed above, the focus of this paper is not to evaluate the economic effects of the earthquake but is instead to apply novel methods of network science to uncover the endogenous mechanisms of interfirm interactions, which are the channels for propagation of economic shocks. By identifying the structure of the dynamic micro-network processes among the largest actors during this challenging period, we aim to pinpoint the potential sources of vulnerability of the resulting macro-structure of the Japanese economy and propose pathways to increase its resilience. Thus, the main hypothesis of this study (in contrast to the typically implicit assumptions found in traditional econometric studies) is that economic links do not exist in isolation. It is highly plausible that firms consider existing alliances and associations among other firms when they choose their business partners. Specifically, this paper tests the four following hypotheses regarding network interdependencies among supply-purchase trading relationships.

\subsubsection{Hypothesis 1: Supply chains are hierarchical}

Influential economic models of supply chains and global production networks emphasize a sequential nature of industrial production in which resources and subsequently intermediate goods move down the linear chains of production (Antràs \& Chor, 2013; Antràs et al., 2012; Costinot et al., 2013; Dixit \& Grossman, 1982; Sanyal, 1983). While collecting the present data, the informants were asked to 
identify interactions in which they purchase goods or services from suppliers and interactions in which they sell goods or services to clients. Hypothesis 1 tests whether supply chains are hierarchical entities in which materials, goods, and services move unidirectionally from primary producers through intermediaries to users (Mentzer et al., 2001) or whether bidirectional flows of goods and services are more common than would be expected by chance. The rejection of this hypothesis would imply that there is no strict hierarchy in dyadic economic interactions (i.e. trading partners can be both a supplier and a client of the same firm) and that firms prefer to obtain supplies from firms that have purchased goods or services from them, possibly as a result of social obligations (Lincoln \& Gerlach, 2004).

The next set of hypotheses extends beyond the dyadic interdependencies between pairs of companies to test how external actors affect trade among pairs of firms. The following two hypotheses are related to the access to and sharing of suppliers, which has been considered one of the main advantages of industrial agglomerations (Amiti \& Cameron, 2007; Puga, 2010; Rosenthal \& Strange, 2001).

\subsubsection{Hypothesis 2: Firms tend to choose suppliers that also supply their trading partners}

Hypothesis 2 predicts that economic interactions are more likely among firms that have common trading partners. Such interactions may occur for several reasons. Firms might be introduced to new potential partners through their existing partners, or firms with mutual partners may be interested in the same markets or work on compatible products. Moreover, firms embedded in a dense network of relationships with mutual partners are less likely to defect (Coleman, 1988; Granovetter, 1985). The formation of trading groups seems to be an important driver of economic exchange, particularly in Japan (Granovetter, 2005). It has been suggested that the tendency to turn to these groups is highest during difficult economic periods (Lincoln \& Gerlach, 2004), which Japan has experienced over the most recent two "lost decades."

\subsubsection{Hypothesis 3: Firms prefer suppliers that are generally popular with other firms}

This hypothesis predicts that firms prefer to obtain supplies from firms that supply to many other firms. It may be more economical to share a supplier with a large number of other firms; suppliers that serve a wider clientele may be able to provide better services, and they may be more credible and relatively easier to notice. Popular suppliers may be considered more desirable and dependable or may be preferred because of economies of scale or because they are able to provide services on popular platforms that are used by other clients or customers. Such tendencies would lead naturally to network centralization, particularly if it is possible to create and maintain links over long distances (Barthélemy, 2011). Increased tendencies toward both network centralization and embeddedness among organizations have also been reported during times of crisis (Robins, 2013).

\subsubsection{Hypothesis 4: Firms avoid suppliers that depend on many other suppliers}

This hypothesis predicts that firms avoid (not necessarily consciously) suppliers that rely on many different sources for the products or services that they require. The 
evidence suggests that such suppliers may fail if any of their sources fail. Firms that were connected to many firms through large supply chains were more likely to experience supply shortages and consequently operational interruptions after the Great East Japan Earthquake (Todo et al., 2014). Thus, firms might have been particularly likely to avoid or disconnect from such suppliers during the period after the earthquake. Case studies also suggest that economic actors may strive to create parallel links with the suppliers of their suppliers in aiming to bypass intermediaries (Tallontire, 2000). From an analytical perspective, the avoidance of suppliers with too many independent sources and the creation of shortcuts to bypass intermediaries both empirically manifest as minimizing the number of firms at distance two in longitudinal networks. Both of these tendencies may also lead to clustering.

As a competing hypothesis to that discussed immediately above, firms might prefer suppliers with diverse sources that cannot be directly accessed, and intermediaries may add value and thus tend not to be bypassed by direct trading and by forming redundant links (Bailey \& Bakos, 1997).

\section{Methods}

\subsection{Data}

This study focuses on the largest firms in the Japanese economy. Of the over one million incorporated firms in Japan, we selected the 500 largest firms in terms of annual sales reported in 2010. The sample ranges from manufacturers to financial institutions and retailers. The sales of these 500 companies amount to approximately one-third of national sales (Tokyo Shoko Research, 2010, Table 1). Economic research on interfirm interactions appears to typically focus on samples of firms within the same industry, but we did not limit this sample to a specific industry because effective supply chain management requires partnerships and strategic alliances with stakeholders and intermediaries across sectors (Cooper et al., 1997; Ellram \& Cooper, 1990). Moreover, "horizontal" keiretsu linkages among firms in different industries are considered to be particularly important for the functioning of the Japanese economy (Lincoln \& Gerlach, 2004). These interindustry links are known to provide support to firms in need during difficult economic periods (Lincoln $\&$ Gerlach, 2004). From the perspective of vulnerability to disasters, interindustrial linkages are crucial: the failure of an electricity, transportation, or communication services provider may disrupt the operations of groups of otherwise disconnected manufacturers or retailers.

The chosen sample size is large enough to include interconnected firms from a variety of industries and regions, but it still allows for the necessary analytic assumption that any actor can reasonably evaluate any other actor in the selection of network partners. This assumption would be less plausible with larger samples and would thus make the modeling of network evolution less realistic. (Incidentally, "500" is also a popular cut-off point in rankings of major corporations, e.g. S\&P 500, Fortune 500, or Financial Times 500.)

The selected firms' representatives were interviewed face-to-face regarding their transaction partners by Tokyo Shoko Research agency. The first wave of data gathering was undertaken between March 2010 and March 2011. The second wave 
Table 1. Description of the top 500 firms by broad industrial categories. Values for 2010 are presented above the values for 2011, and the values for 2011 are in italics. All statistics (except for $N$ ) are median values for firms in each category. Remoteness is the median geographical distance to the headquarters of all top 500 companies.

\begin{tabular}{|c|c|c|c|c|c|}
\hline & \multirow[b]{2}{*}{$N$} & \multicolumn{4}{|c|}{ Median firm statistics } \\
\hline & & $\begin{array}{l}\text { Number of } \\
\text { clients }\end{array}$ & $\begin{array}{l}\text { Number of } \\
\text { suppliers }\end{array}$ & $\begin{array}{c}\text { Remoteness } \\
{[\mathrm{km}]}\end{array}$ & $\begin{array}{c}\text { Sales } \\
\text { ['000 Yen] }\end{array}$ \\
\hline \multirow{2}{*}{$\begin{array}{r}\text { Construction } 2010 \\
2011\end{array}$} & \multirow[t]{2}{*}{22} & 5.5 & 4.5 & \multirow[t]{2}{*}{7.2} & $3.91 \mathrm{E}+08$ \\
\hline & & 5 & 4 & & $4.04 E+08$ \\
\hline \multirow[t]{2}{*}{ Energy } & \multirow[t]{2}{*}{13} & 6 & 8 & \multirow[t]{2}{*}{305.1} & $1.03 \mathrm{E}+09$ \\
\hline & & 6 & 9 & & $1.12 E+09$ \\
\hline \multirow[t]{2}{*}{ Finance } & \multirow[t]{2}{*}{56} & 0 & 0 & \multirow[t]{2}{*}{5.2} & $6.70 \mathrm{E}+08$ \\
\hline & & 0 & 0 & & $6.94 E+08$ \\
\hline \multirow[t]{2}{*}{ ICT } & \multirow[t]{2}{*}{20} & 4 & 4.5 & \multirow[t]{2}{*}{5.3} & $4.26 \mathrm{E}+08$ \\
\hline & & 4 & 6 & & $4.30 E+08$ \\
\hline \multirow[t]{2}{*}{ Manufacturing } & \multirow[t]{2}{*}{161} & 6 & 4 & \multirow[t]{2}{*}{7.3} & $4.92 \mathrm{E}+08$ \\
\hline & & 5 & 4 & & $5.27 E+08$ \\
\hline \multirow[t]{2}{*}{ Medical care and welfare } & \multirow[t]{2}{*}{8} & 0 & 0 & \multirow[t]{2}{*}{5.0} & $1.55 \mathrm{E}+09$ \\
\hline & & 0 & 0 & & $1.63 E+09$ \\
\hline \multirow[t]{2}{*}{ Mining } & \multirow[t]{2}{*}{2} & 4 & 2 & \multirow[t]{2}{*}{4.4} & $3.17 \mathrm{E}+08$ \\
\hline & & 4 & 3 & & $4.49 E+08$ \\
\hline \multirow[t]{2}{*}{ Other services } & \multirow[t]{2}{*}{15} & 1 & 1 & \multirow[t]{2}{*}{21.7} & $3.29 \mathrm{E}+08$ \\
\hline & & 1 & 1 & & $3.46 \mathrm{E}+08$ \\
\hline \multirow{2}{*}{$\begin{array}{l}\text { Personal services and } \\
\text { entertainment }\end{array}$} & \multirow[t]{2}{*}{9} & 0 & 1 & \multirow[t]{2}{*}{7.7} & $4.07 \mathrm{E}+08$ \\
\hline & & 0 & 1 & & $3.56 E+08$ \\
\hline \multirow{2}{*}{$\begin{array}{l}\text { Professional and } \\
\text { technical services }\end{array}$} & \multirow[t]{2}{*}{15} & 2 & 3 & \multirow[t]{2}{*}{4.7} & $3.90 \mathrm{E}+08$ \\
\hline & & 2 & 2 & & $3.28 E+08$ \\
\hline Real estate & 21 & 2 & 5 & 5.3 & $4.76 \mathrm{E}+08$ \\
\hline & & 2 & 5 & & $4.27 E+08$ \\
\hline Retail & 139 & 3 & 5 & 8.0 & $4.58 \mathrm{E}+08$ \\
\hline & & 3 & 5 & & $4.89 E+08$ \\
\hline Transport and postal & 19 & 2 & 4 & 5.2 & $7.96 \mathrm{E}+08$ \\
\hline & & 2 & 4 & & $8.26 E+08$ \\
\hline
\end{tabular}

of data gathering was undertaken between March 2011 and March 2012. The time between the two surveys was 12 months or more for $98 \%$ of the companies. In this paper, we refer to the data collected from the first wave as "2010 data" and the data collected from the second wave as "2011 data." The informants were asked to name up to 24 of their main suppliers or buyers of goods or services. No other details about the interactions (such as the volumes of the transactions) were requested. Links to companies outside the top 500 firms are not considered in the present analysis.

Addresses of all headquarters were converted to geographical coordinates (using a service provided by Center For Spatial Information Science, University of Tokyo) from which the direct physical distance between each firm was calculated. The locations of the sample firms' branches and plants are not known, which is a limitation of this study. 
Most of the companies in the sample have headquarters in the Tokyo Metropolitan Region (334) or its vicinity (24 firms have headquarters in Kanagawa, Chiba, Kawasaki, and Saitama). The second most popular location is Osaka (53). The remainder of the companies are scattered in various locations around Japan. Only four of the top 500 firms have headquarters in Tohoku region prefectures, which was the region that suffered direct physical damage from the Great East Japan Earthquake and tsunami (three in Miyagi and one in Fukushima prefecture). We found no relevant changes for these companies during this period (except for one link, all these companies maintained the same number of suppliers and clients in both years and their aggregate sales changed by only $1.5 \%$ between the two years). Nevertheless, using methods described in the following section, we tested whether the networks surrounding the Tohoku region evolved in any way that was different from the general tendencies that were uncovered herein. We examined 11 firms with headquarters located in Aomori, Sendai, Yamagata, Niigata, Fukushima, Tochigi, and Ibaraki and also all 23 clients of these firms that are located outside of the Tohoku region by constructing dummy variables to identify these firms.

\subsection{Stochastic actor-oriented modeling}

After describing the structure and spatial distribution of the interfirm networks in 2010 and 2011, we analyze the microprocesses that lead to the observed macro-level network structures. Network interdependencies regarding the formation of economic interaction structures can be quantified via stochastic actor-oriented models while controlling for the possible effects of distance. Stochastic actor-oriented models are statistical parametric models for evolving networks (Ripley et al., 2012; Snijders et al., 2013). The technical details of this approach may be found in the appendix and in the cited works of T. A. B Snijders and his colleagues (Snijders, 2001; Snijders et al., 2010; Steglich et al., 2010). This modeling approach enables us to uncover firms' preferences in selecting their suppliers.

We assume that firms choose their suppliers to maximize their utility. Therefore, we code the observed network data for the model input such that links are directed from clients to suppliers. Furthermore, stochastic actor-oriented models are based on the assumption that actors may consider any of the other actors in the entire network to be their potential partners; this assumption seems reasonable given the limited sample of major players in the economy. The models are constructed such that firms may choose their suppliers (i.e. their outgoing network ties) based on their individual characteristics (such as firm size or industry type), their pair-wise characteristics (such as physical distance), and endogenous network characteristics (such as the number of mutual partners) (Table 2). The goal of the simulation in this study was to estimate the direction and statistical significance of these effects for the log odds of the creation and maintenance of supply-purchase links between pairs of firms in the period around the Great East Japan Earthquake.

Using methods developed by Lospinoso and Snijders (2011), we tested the goodness of fit of the model on the overall fundamental network characteristics that were not explicitly modeled by any of the included micro-effects (specifically, the degree distribution, geodesic distance distribution, and triad census). Guided by our hypotheses, we searched by trial and error for a model specification with an 
Table 2. Formulas for $s_{k i}(x)$ selection effects in network $x$ for ego $i$ and alters $j$, other actors $h$, and actors' attributes $v . w_{i j}$ is (the natural logarithm of) the distance between $i$ and $j$. Arrows point from clients to suppliers; dashed arrows signify trading relationships that are likely to be created and maintained if the effect is positive.

\begin{tabular}{lcc}
\hline \hline Hypothesis effect name & Mathematical formula & Graphical representation \\
\hline $\begin{array}{l}\text { Spatial effects } \\
\text { Dyadic physical distance }\end{array}$ & $\sum_{j} x_{i j}\left(w_{i j}-\operatorname{mean}\left(w_{i j}\right)\right)$ & $\underset{j}{\text { Effects of firms' characteristics } v \text { on trade }}$ \\
Client's attributes & $\sum_{j} x_{i j} v_{i}$ & $\sum_{j} x_{i j} v_{j}$ \\
Supplier's attributes & $\sum_{j} x_{i j}\left(\operatorname{sim}_{i j}^{v}-\overline{\left.\operatorname{sim}^{v}\right)}\right.$ & $\sum_{j} x_{i j} I\left\{v_{i=} v_{j}\right\}\left\{\begin{array}{c}I\left\{v_{i=} v_{j}\right\} \\
0\end{array}\right.$
\end{tabular}

Endogenous trade network interdependencies

Hypothesis 1

Reciprocity

$\sum_{j} x_{i j} x_{j i}$

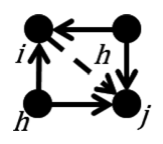

Hypothesis 2

Transitive mediated triplets

$$
\sum_{j, h} x_{j i} x_{i h} x_{j h}
$$

Hypothesis 3

Number of actors at distance two

Hypothesis 4

Indegree popularity (sqrt)

Control for network density

$$
\#\left[\mathrm{j}\left|x_{i j}=0, \max \left(x_{i h} x_{h j}\right)\right\rangle 0\right]
$$

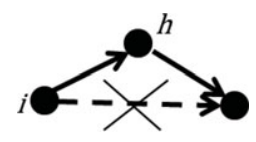

$$
\sum_{j} x_{i j} \sqrt{\sum_{h} x_{h j}}
$$

Outdegree

Control for firms that do not receive any supplies

Truncated outdegree

$$
\sum_{j} x_{i j}
$$

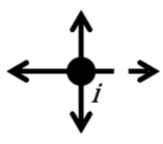

$\min \left(x_{i+}, c\right) ; c=1$
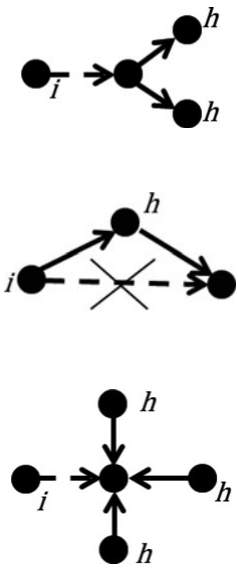

$\boldsymbol{\theta}_{\bar{i}} \rightarrow$

Note: $x_{i j}=1$ if there is a directed tie from $i$ to $j$ and 0 otherwise ${ }^{b} \overline{\operatorname{sim}^{v}}$ is the mean of all similarity scores, which are defined as $\operatorname{sim}_{i j}^{v}=\frac{\Delta-\left|v_{i}-v_{j}\right|}{\Delta}$ with $\Delta=\max \left|v_{i}-v_{j}\right|$. 
acceptable fit. We aimed for the simulations to reproduce the fundamental network characteristics such that the observed statistics were within their $90 \%$ confidence intervals. The meaning of the effects in the final model is explained in Table 2. The fit of the models is discussed in detail in the appendix.

To estimate the log odds of an interfirm trade link in the presented models, we use the straight physical distance in log form, which closely corresponds to the most commonly used functional form of distance in gravity models for estimating economic and social interactions (Anderson, 1979; Bergstrand \& Egger, 2007; Daraganova et al., 2012; Koskinen \& Lomi, 2013; Preciado et al., 2012; Wilson, 1967; Woo-Sung et al., 2008). The marginal costs of business interactions are likely to decrease with distance as the main mode of transport and its speed changes (walking to the next street block, train ride to another city, or air travel to another island; see Wilkerson et al., 2013). The logarithmic transformation also has desirable properties, particularly considering the centralized locations of headquarters and the highly skewed distribution of distances among them. Most partners are located within $10 \mathrm{~km}$ from one another, but a non-negligible number of ties span hundreds of kilometers (Table 3).

\section{Results}

\subsection{Descriptive results}

The stability of the relations among Japanese firms even during this presumably turbulent economic period is remarkable. Although there was a sufficient amount of micro-level change in the observed networks to allow for statistical modeling with a limited number of effects (Table 4), the networks in 2010 and 2011 are almost indistinguishable in their aggregate characteristics. In both years, the average number of links per firm is approximately 4.6, and the average local clustering coefficient (i.e. the proportion of partners of each firm that are also partners with one another, calculated on an undirected network) is 0.16 . This level of clustering is almost ten times higher than the expected level of clustering for a network of the same density with independent links. Furthermore, the median numbers of clients and suppliers in each industry (Table 1) and skewed degree distributions (Table 4, Figure 3) remain nearly unchanged.

Figure 1 shows the network of economic interactions on a map of Japan and Figure 2 reveals the topology of this network aggregated at the prefecture level. Tokyo, Osaka, and Aichi (which hosts Toyota Motor Corporation and its suppliers) are at the center of the network. (The capital of Aichi is Nagoya, Figure 1.) The prefectures most directly affected by the Great East Japan Earthquake, Miyagi and Fukushima, have fewer large firms with connections outside of their prefectures.

Table 3 highlights the interdependency of each sector of the Japanese economy on other sectors in terms of supply networks. The table provides an intuitive description of the relative position of each sector in the web of multidirectional flows of goods and services. Manufacturing firms are the main clients of energy and mining firms. Within the top 500, 63\% and $41 \%$ of clients of energy and mining firms are manufacturing firms, respectively. Energy firms are also strongly linked with other energy firms; $33 \%$ of the clients of energy firms are other energy firms. Further downstream, most clients of manufacturing firms are other manufacturing firms 
Table 3. Intersectoral input-output table. Each cell displays the proportion of links that the industrial sector named on the top of each column receives from the sector named in the beginning of each row. For example, among the 500 largest Japanese firms, $41 \%$ of clients of energy firms are manufacturing firms, $33 \%$ are other energy firms, and $11 \%$ are transport firms.

\begin{tabular}{|c|c|c|c|c|c|c|c|c|c|c|c|c|c|}
\hline & Construction & Energy & Finance & ICT & Manufacturing & $\begin{array}{l}\text { Medical } \\
\text { care and } \\
\text { welfare }\end{array}$ & Mining & $\begin{array}{c}\text { Other } \\
\text { services }\end{array}$ & $\begin{array}{c}\text { Personal } \\
\text { services and } \\
\text { entertainment }\end{array}$ & $\begin{array}{c}\text { Professional } \\
\text { and technical } \\
\text { services }\end{array}$ & $\begin{array}{l}\text { Real } \\
\text { estate }\end{array}$ & Retail & $\begin{array}{c}\text { Transport } \\
\text { and } \\
\text { postal }\end{array}$ \\
\hline Construction & 0.30 & 0.06 & 0.00 & 0.02 & 0.03 & NA & 0.00 & 0.05 & 0.00 & 0.05 & 0.04 & 0.05 & 0.00 \\
\hline Finance & 0.01 & 0.00 & 0.60 & 0.01 & 0.00 & NA & 0.00 & 0.08 & 0.50 & 0.12 & 0.09 & 0.02 & 0.05 \\
\hline ICT & 0.02 & 0.00 & 0.00 & 0.24 & 0.05 & NA & 0.00 & 0.00 & 0.00 & 0.07 & 0.11 & 0.02 & 0.00 \\
\hline Manufacturing & 0.22 & 0.41 & 0.20 & 0.18 & 0.41 & NA & 0.63 & 0.14 & 0.25 & 0.38 & 0.23 & 0.37 & 0.25 \\
\hline Mining & 0.00 & 0.00 & 0.00 & 0.00 & 0.00 & NA & 0.00 & 0.00 & 0.00 & 0.02 & 0.00 & 0.00 & 0.00 \\
\hline Other services & 0.02 & 0.01 & 0.00 & 0.01 & 0.02 & NA & 0.00 & 0.27 & 0.00 & 0.05 & 0.06 & 0.02 & 0.00 \\
\hline $\begin{array}{l}\text { Personal services } \\
\text { and } \\
\text { entertainment }\end{array}$ & 0.00 & 0.01 & 0.00 & 0.00 & 0.00 & NA & 0.00 & 0.00 & 0.00 & 0.02 & 0.00 & 0.01 & 0.05 \\
\hline $\begin{array}{l}\text { Professional and } \\
\text { technical } \\
\text { services }\end{array}$ & 0.01 & 0.01 & 0.00 & 0.17 & 0.01 & NA & 0.00 & 0.00 & 0.00 & 0.07 & 0.02 & 0.01 & 0.02 \\
\hline
\end{tabular}


Table 4. The sales of the top 500 firms and the spatial distribution of their headquarters and their partners.

\begin{tabular}{lcccc}
\hline \hline & Minimum & Median & Mean & Maximum \\
\hline Sales in 2010 ('000 Yen) & $2.5^{*} 10^{8}$ & $5.0^{*} 10^{8}$ & $9.3^{*} 10^{8}$ & $2.0^{*} 10^{10}$ \\
Log of sales in 2010 & 19.3 & 20.0 & 20.2 & 23.7 \\
Distance distribution among all pairs of & 0.1 & 26.3 & 195.0 & $1,592.0$ \\
$\quad$ top 500 firms [km] & & & & \\
Log of distance among firms & -3.0 & 3.3 & 3.6 & 7.4 \\
Median distance to all firms [km] & 4.3 & 6.7 & 122.9 & 965.9 \\
Trade link length distribution [km] & & & & \\
$\quad 2010$ & 0.0 & 9.6 & 157.0 & $1,267.0$ \\
$\quad 2011$ & 0.0 & 9.8 & 159.1 & $1,267.0$ \\
Firms' median trade link length [km] & & & & \\
$\quad 2010$ & 0.0 & 7.6 & 129.2 & 968.3 \\
2011 & 0.0 & 7.5 & 127.0 & 968.3 \\
\hline \hline
\end{tabular}

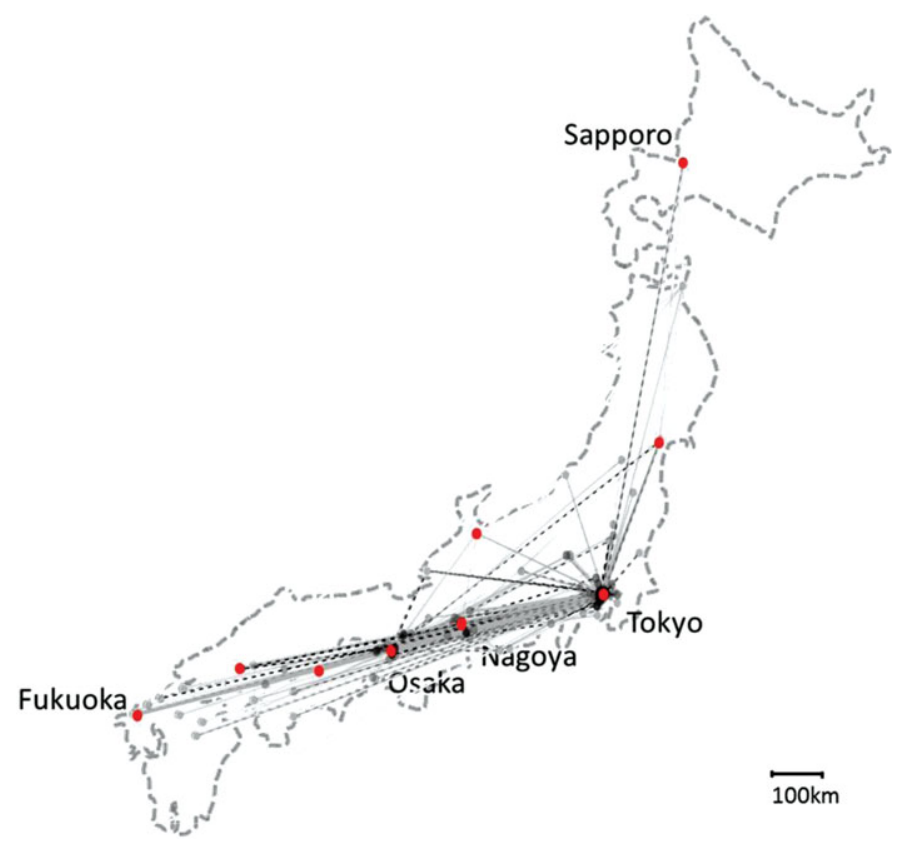

Fig. 1. Geographical distribution of trading links among the largest 500 companies in Japan in 2010 and 2011. Dashed lines represent links that were reported in only one of the two years. Red nodes depict energy firms. (Nodes depicting non-energy firms and all links are semitransparent and thus are more visible in regions in which their geographical density is high). (Color online)

$(41 \%)$ and retail firms $(38 \%)$. The main commercial clients of retail firms are other retail firms $(40 \%)$.

Table 4 quantitatively illustrates the extreme extent of geographical concentration of the headquarters of the largest Japanese companies. Half of the headquarters for the top 500 firms are located within a $4.3 \mathrm{~km}$ radius of the most centrally located firm in Tokyo. Most of the top 500 firms are located more than $968 \mathrm{~km}$ from the most remote firm. 


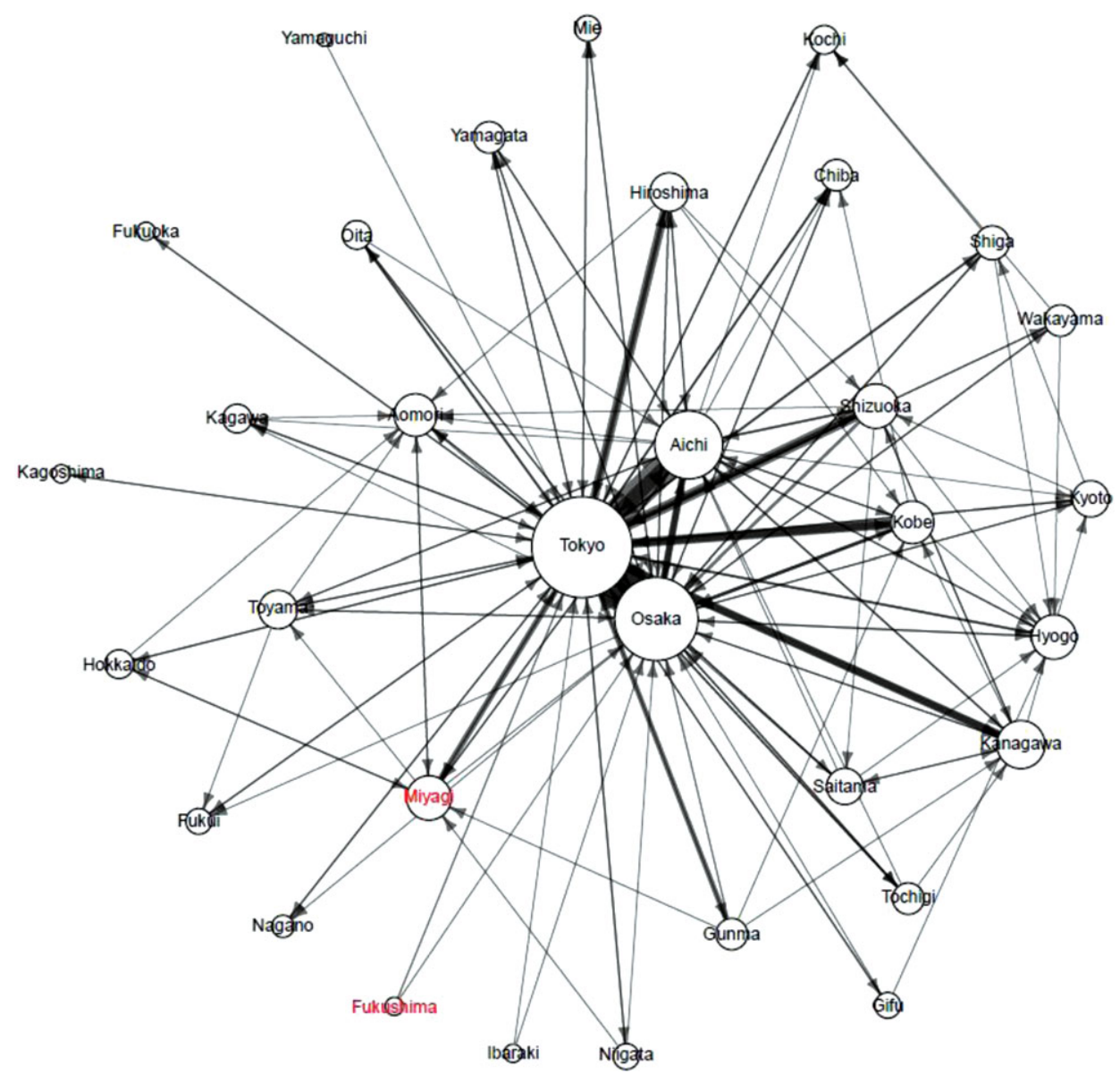

Fig. 2. The trade network aggregated at the prefectural level. Topologically central prefectures are located near the center of the plot. Prefectures linked through more industries are connected with thicker lines and prefectures with connections to more other prefectures are represented by larger nodes. The arrows point from clients to suppliers. Fukushima and Miyagi - the prefectures most directly affected by the Great East Japan Earthquake - are highlighted. (Color online)

As a result, most links are short in geographical distance. In both years, onehalf of trading partners had headquarters within $10 \mathrm{~km}$ from one another. (The most proximate trading partners are located in the same block; the average is approximately $160 \mathrm{~km}$; and the most distant partners trade between the northeast and southwest corners of the main island of Honshu and are over 1,000 km apart; Table 4.) The relation between geographical centrality and network centrality is not straightforward. For example, the headquarters of the largest financial and medical institutions agglomerate in the center of Tokyo close to individual customers and public institutions. However, most of these institutions do not have trading links with other top 500 corporations. Additionally, firms providing "professional services" (e.g. recruitment or advertisement) and entertainment are geographically central but peripheral in the network of interactions among major firms (Table 1). 
Table 5. Network density and network change.

\begin{tabular}{lcc}
\hline \hline Overall network characteristics & 2010 & 2011 \\
\hline Network density & 0.009 & 0.009 \\
Mean degree & 4.63 & 4.62 \\
Outdegree skewness & 1.91 & 1.82 \\
Indegree skewness & 3.23 & 3.12 \\
Number of links & 2,317 & 2,255 \\
Mean local clustering & 016 & 0.16 \\
Missing fraction & 0.00 & 0.02 \\
\hline Link changes between 2011 and 2012 & & \\
\hline Preserved relationships & & \\
Number of changed relationships & & 3,120 \\
New trading relationships & & 135 \\
Abandoned relationships & & 170 \\
Jaccard index & & 0.87 \\
Ordered pairs of firms without a link in both years & 241,117 \\
Missing & $5,958(2 \%)$ \\
\hline \hline
\end{tabular}

Large energy firms are idiosyncratic. In contrast to other sectors, the energy sector in Japan is highly geographically decentralized, and the headquarters of major firms in the energy sector do not agglomerate in the capital region (Figure 1; Table 1). The energy firms in the sample include electric power firms and gas firms, and these firms have a noticeably high number of connections to other firms. They are not only among the main suppliers of many large firms (which is explainable by the importance of energy for industrial production) but are also important clients of numerous other firms. Because of their distinct geographical and network characteristics, we pay special attention to energy firms in the main statistical analysis.

Figure 4 displays the 1-step and 2-step neighborhoods of an energy company. Inter-industrial links, which are neglected in network studies on single industries, can be observed in this image. Although we do not have data related to the types of goods and services "flowing" through these links, these flows likely relate to the procurement of construction services to build facilities and the purchase of equipment and fuel from manufacturers, general contractors, and trading companies. On the client side, these links may relate to the distribution of energy to factories, construction sites, or offices. The failure or success of such an energy firm would affect major firms from diverse sectors that are both upstream and downstream.

\subsection{Estimation results}

In this section, the effects of network interdependencies on the formation of trade structures are assessed by using stochastic actor-oriented models. First, we present a model in which we control for general network density (Table 5) and include the effects of distance and firm size, as proxied by sales (Model 1 in Table 6). 

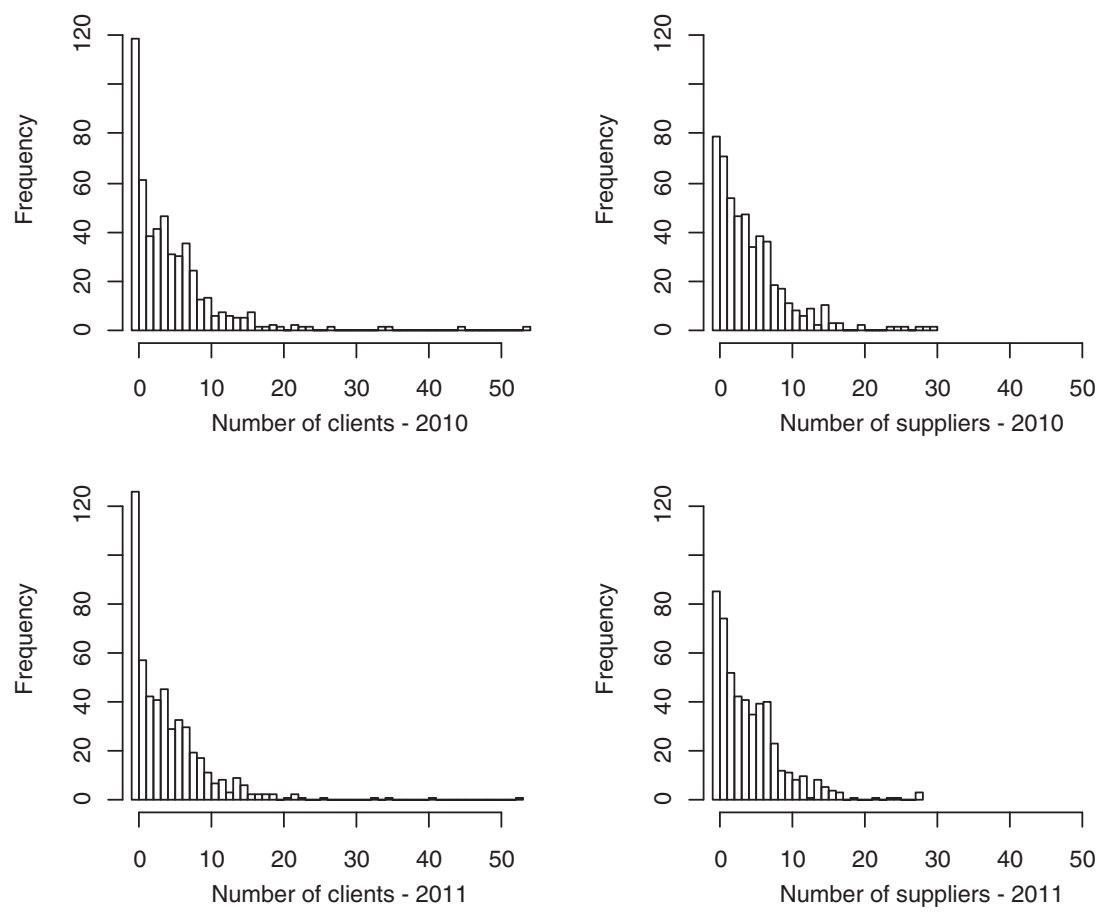

Fig. 3. Distribution of clients and suppliers among the top 500 firms.

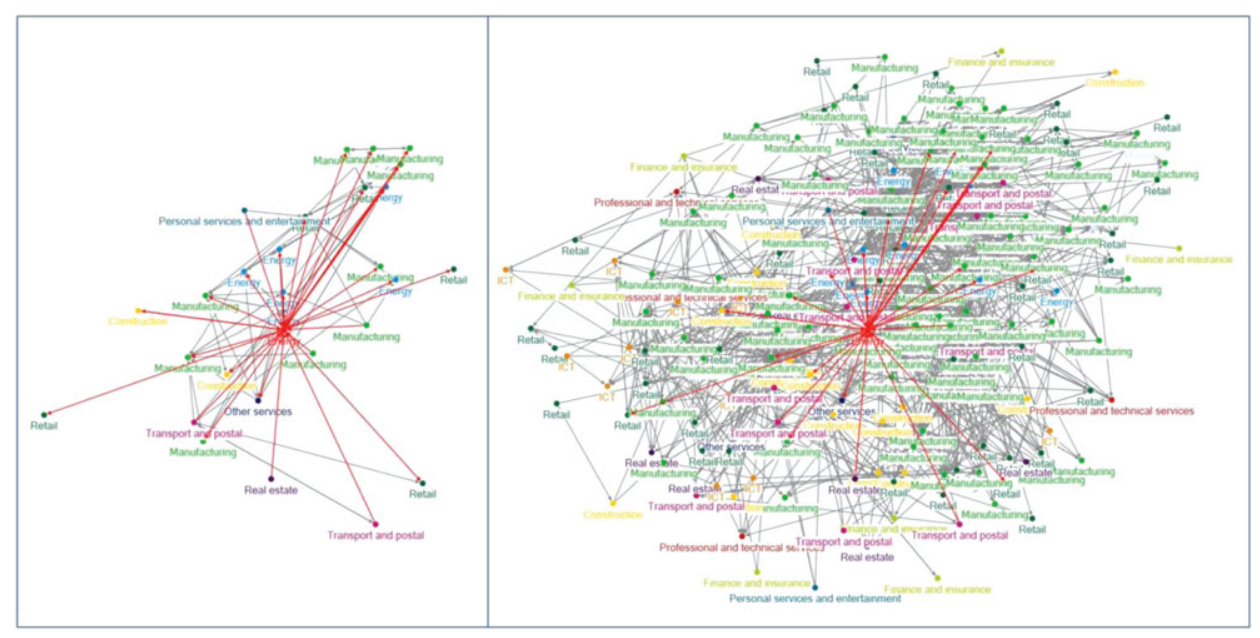

Fig. 4. One-step (left) and two-step (right) network neighborhoods of one energy firm within the top 500 firm network. Red lines indicate direct links of the firm to its suppliers and clients; node labels and their colors indicate the industrial sector of each firm. (Color online)

The distance between headquarters does not have a clear impact on links between energy firms and non-energy firms. As discussed above, energy firms have headquarters attached to their regions of origin, whereas non-energy firms tend to concentrate in the largest urban agglomerations. However, the distance between headquarters has a significantly negative relationship on the probability of links 
Table 6. Stochastic actor-oriented model estimating the log odds of creating and maintaining a link.

\begin{tabular}{|c|c|c|}
\hline \multirow[b]{2}{*}{ Firm characteristics and geography } & \multicolumn{2}{|c|}{ Parameter estimates (Standard errors) } \\
\hline & $\begin{array}{l}\text { (1) } \\
\text { Independent } \\
\text { links }\end{array}$ & $\begin{array}{l}\text { (2) } \\
\text { Interdependent } \\
\text { links }\end{array}$ \\
\hline Dyadic physical distance $[\log \mathrm{km}]$ & $0.254(0.165)$ & $0.176(0.158)$ \\
\hline Client's size [log of sales in thousands of Yen] & $-0.149(0.143)$ & $-0.279 * *(0.126)$ \\
\hline $\begin{array}{l}\text { Supplier's size [log of sales in thousands of } \\
\text { Yen] }\end{array}$ & $0.186 * *(0.089)$ & $0.251 * *(0.119)$ \\
\hline Size similarity & $0.187(0.469)$ & $-0.167(0.528)$ \\
\hline Client is an energy firm & $2.681 * * *(0.655)$ & $1.403(0.651)$ \\
\hline Supplier is an energy firm & $1.716^{* * *}(0.539)$ & $1.709 * * *(0.548)$ \\
\hline $\begin{array}{l}\text { Link between two energy firms or two } \\
\text { non-energy firms }\end{array}$ & $2.066^{* * *}(0.614)$ & $1.296^{*}(0.663)$ \\
\hline $\begin{array}{l}\text { Interaction of link between two energy firms } \\
\text { or two nonenergy firms \& distance }[\log \mathrm{km}]\end{array}$ & $-0.324 *(0.166)$ & $-0.225(0.161)$ \\
\hline \multicolumn{3}{|l|}{ Network interdependencies } \\
\hline Reciprocity & & $1.371^{* * *}(0.311)$ \\
\hline Transitive mediated triplets & & $0.247^{* * *}(0.088)$ \\
\hline Number of actors at distance two & & $-0.201 * * *(0.033)$ \\
\hline Indegree popularity [sqrt] & & $0.680 * * *(0.092)$ \\
\hline Outdegree & $-4.808 * * *(0.599)$ & $-4.965 * * *(0.658)$ \\
\hline Truncated outdegree & & $-2.310 * * *(0.527)$ \\
\hline
\end{tabular}

Statistical significance levels: $* 10 \%, * * 5 \%, * * * 1 \%$.

between pairs of non-energy firms (which form the vast majority of links) and the probability of links between pairs of energy firms.

To illustrate the relative strength of the coefficient estimates for distance $(-0.324)$ and firm size (0.186), let us consider a firm that chooses between suppliers A and B. The firm would choose either A or B with a similar probability if the distance to A was half of that to B but if B were three times the size of A, ceteris paribus. ${ }^{1}$

In Model 2, we add endogenous network effects, which improve the fit of the model (Model 2 in Table 6; Appendix). The addition of these network interdependencies weakens the distance effect below the threshold of significance for this dataset with a limited amount of network change. The tendency of energy firms to reach more suppliers during this period also becomes insignificant under this model.

The following section reports the implications of the estimation results for the research hypotheses.

\section{Hypothesis 1}

Two firms may be both suppliers and clients to one another. Reciprocity drives the formation of trading networks, and firms are more likely to buy goods and services from partners that buy goods and services from them.

1 Both distance and size are included in the model in their logarithmic form. Two options have identical expected utility if (Distance to A / Distance to B $)^{\wedge}(0.324 / 0.186)=($ Size A / Size B). 


\section{Hypothesis 2}

Firms prefer suppliers when they have clients in common with one another. (See the positively significant effect of transitive mediated triplets in Table 6.)

\section{Hypothesis 3}

When supplier size is controlled for, popular suppliers that are shared by many firms are particularly sought out (expressed by the positively significant indegree popularity effect).

\section{Hypothesis 4}

Firms attempt to minimize (not necessarily on purpose) the number of independent suppliers that supply their suppliers (expressed by the negatively significant "number of actors at distance two effect").

After endogenous effects are accounted for, the effect of client size becomes negatively significant. This effect is negatively correlated with the transitive mediated triplets $(r=-0.35)$ and positively correlated with the number of actors at distance two $(r=0.20)$. This association with effects representing network closure (the latter effect inversely) suggests that smaller companies in the sample are particularly constrained by the existing clique structures of companies.

In addition to endogenous network tendencies, industry characteristics are important. Specifically, energy firms are clearly important suppliers, and interactions between energy firms are frequent. The combination of all the tendencies discussed above (i.e. the possibility of trade between remote energy firms and non-energy firms, reciprocal exchanges among partners, the creation and maintenance of links within groups with preexisting links, network centralization around firms with many clients, and the importance of the energy supply) leads to the formation of densely interconnected networks revolving around energy firms, despite their relatively peripheral locations (Figure 5).

Finally, we tested whether firms with headquarters situated in the Tohoku region and surrounding areas reconfigured their networks differently from other major firms in this period around the Great East Japan Earthquake. However, we found no significant effect on firms' activities in terms of creating and maintaining links or on firms' popularity as suppliers with respect to firms that were located in the prefectures that were directly affected by the disaster-or that neighbor those directly affected prefectures or that had suppliers in either of these areas. Moreover, we found neither assortativity nor dissassortativity regarding location in and around the affected areas. Overall, considering the headquarters location of these top 500 firms or their suppliers in and around the impacted areas did not significantly alter the more parsimonious models that are presented in this paper.

\section{Ties that bind: discussion and conclusion}

Major Japanese firms agglomerate their headquarters spatially. The descriptive and estimation results jointly suggest that endogenous network processes operating on the clustered network structure that was formed among the spatially concentrated 


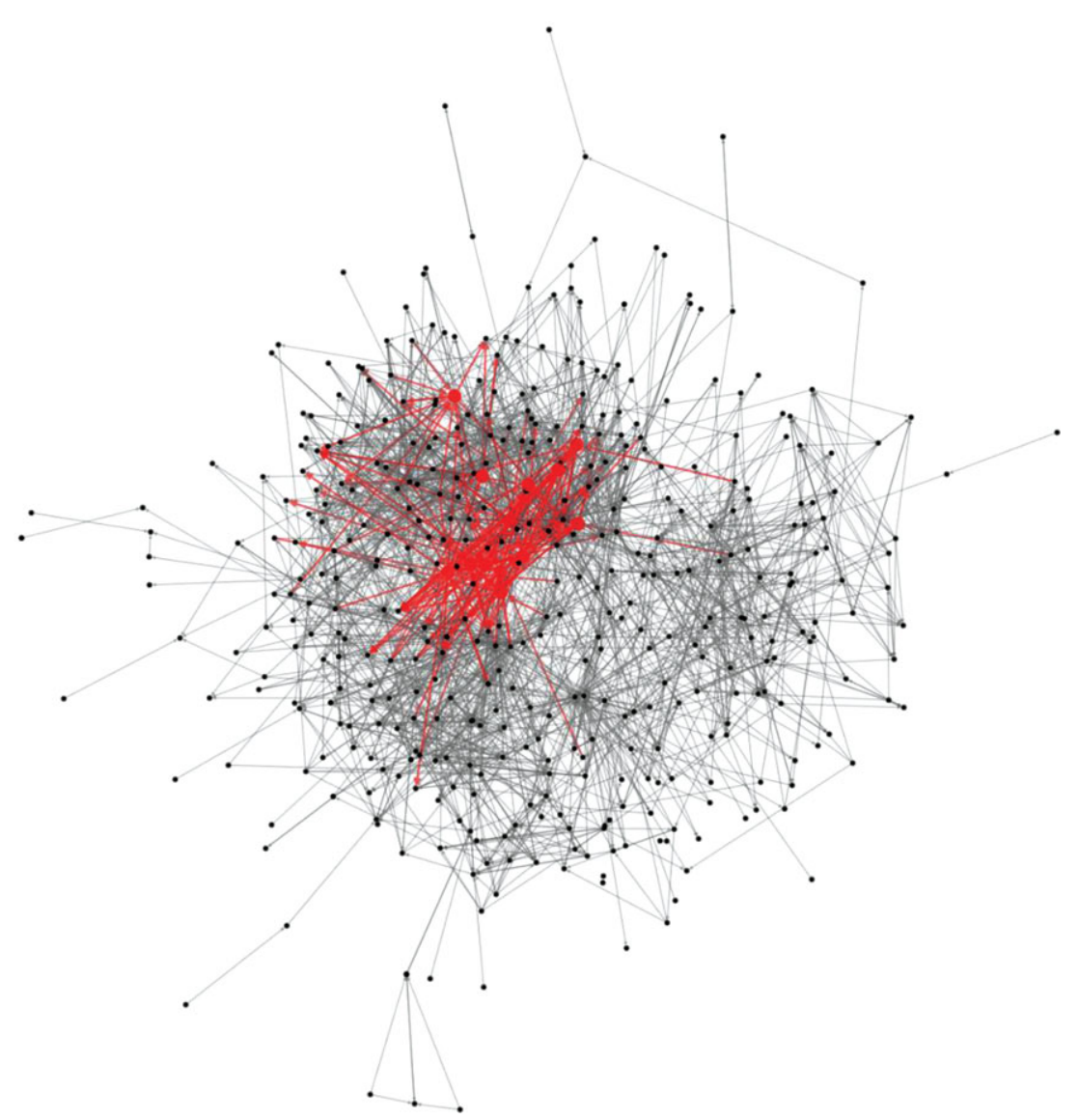

Fig. 5. Network of economic links among the top 500 companies displayed by using Harel-Koren (2002) layout. Energy companies and their links are highlighted in red. (Color online)

firms in the network sustain short links within network clusters and discourage the creation of long links to outsiders.

These results provide empirical evidence that trade links are not statistically independent, which is an assumption that is commonly made in influential theoretical economic models and empirical regression analyses on trade. The confirmed tendency toward bidirectional trade and the formation of loops suggests that "supply chains" are not simply connected chains of firms through which goods flow from one side to the other. The observed creation of company cliques, loops, and bidirectional trade links may be motivated by a collective identity and a mutual exchange of favors among groups of long-term associates (Lincoln \& Gerlach, 2004).

We find no evidence that the tendencies toward clustering and centralization and the prominence of energy companies are unique to this period around the Great East Japan Earthquake. Clustering, degree distribution skewness, and the median degree of energy companies have not increased after the disaster (Table 1, Table 4). Instead, the already highly uneven popularity of suppliers and the clustered nature of the original economic network were sustained by the endogenous micromechanisms contained therein. Although hundreds of links changed during the 
observed period (Table 4), new link creation and old link dissolution tended to maintain the original macro-level network patterns. Firms tended to form alliances within the same network cliques and with established and prominent firms.

Surprisingly, this dynamic seemed to be unaffected by the the Great East Japan Earthquake; these effects are neither stronger nor weaker among firms geographically or topologically closer to the most affected areas. Whereas previous general reports and analysis of datasets consisting mostly of small companies suggested that firms actively substituted their partners in the affected areas after the earthquake (Carvalho et al., 2014; Nakajima \& Todo, 2013), we do find no such tendency among the major economic actors. Notably, in contrast to small firms, exogenous shocks to major firms with headquarters in Tohoku and to their partners did not visibly alter the endogenous formation mechanisms of trade networks linking large-scale organizations that are responsible for a significant proportion of Japan's national output.

Sharing suppliers is considered to be an important driver of industrial agglomeration (Amiti \& Cameron, 2007; Puga, 2010; Rosenthal \& Strange, 2001). Major Japanese companies prefer to "share" suppliers with many other firms and prefer suppliers that also share their suppliers within the group over independent sources outside the trusted company clique. The observed tendencies suggest that links are likely to be created among actors and in parts of the network in which there are links already. The resulting locally dense network structures may promote group identity, foster generalized trust, and lower transaction costs. Membership in such groups also provides access to inside information (Kim \& Nofsinger, 2005). However, such partnerships may be difficult to reconfigure in times of need (Granovetter, 2005). The identified mechanism sustains the status quo of the established groups with advantageous positions in the existing network and may limit the diversity of available resources and information among Japanese firms, which may be a source of vulnerability in a rapidly changing environment. These findings echo the findings of Lincoln and Gerlach (2004) that the largest Japanese manufacturing firms are embedded in network structures that offer only limited degrees of freedom.

It has been suggested that new firms are important for the revitalization of the Japanese economy (Motohashi, 2008). However, without policies facilitating new firm entry, new actors and outsiders face an uphill battle in an environment that is characterized by networks of long-term relationships and preferences for established groups and well-recognized firms.

Overall, the formation and maintenance of cliques seems to be the driving force of trade partner selection among the largest Japanese companies. Although this intensive link interdependency that acts in combination with the significant tendency for pairs of companies to trade in both directions contradicts fundamental assumptions of standard econometric analysis of trade, this finding may not seem surprising to network scholars because tendencies toward transitive closure can be found in many network models of social interactions. However, recent research shows that firms' preferences for transitive closure does not predominate in every industry. Automobile manufacturing, which is probably the most competitive sector of the Japanese economy globally, does not currently display the clustering tendencies that were found in the present study (Matous \& Todo, 2015). 
The interfirm micro-networking tendencies during this period that were revealed in this study enable us to theorize how systemic shocks propagate across the country and build up into macro-economic shocks. Fortunately, no major company was permanently eliminated and apparently no links among these companies were destroyed as a direct result of this disaster. Nevertheless, even without a direct observation of an exogenous node or link removal, the analysis in this study uncovered the mechanisms through which energy and non-energy companies construct their networks across the Japanese territory and enabled us to explain how the effects of the earthquake spread and to estimate the type of risks facing the Japanese economy in terms of future possible shocks. The reported endogenous tendencies combined with the extreme geographical clustering of the largest firms' headquarters may be a source of vulnerability to natural disasters for Japanese firms. Mega-suppliers or entire industrial clusters might be damaged if a disaster hits a main urban center in Japan, such as Tokyo, which lies on a major earthquake fault (Sato et al., 2005).

Energy firms are an exception. Energy producers are central players in the national economic network because they not only provide electricity to many companies but also are important clients of major construction firms, manufacturers, and trading companies. However, in contrast to those major firms in other sectors, the centers of operations of major energy firms are distributed across all the regions of Japan.

Two implications arise from the geographical and network position of energy firms. A disaster in any region may affect an energy producer and cause temporary shocks through long links to firm centers located in main urban agglomerations. However, when natural disasters strike main urban agglomerations, remote energy producers may be able to provide electricity and support to their partners whose headquarters have been affected. From this perspective, it is also recommended that the expansion of the electric power sharing capacities between east and west Japan continue.

Supporting the development of business centers in other vital sectors outside Tokyo is also worth considering. However, under the current network conditions in Japan, most major firms would be unlikely to accept the cost of formal and informal interactions over longer distances with firms and governmental institutions in Tokyo (Lincoln \& Gerlach, 2004), unless a critical mass of industrial headquarters and institutions are attracted to new locations.

The geographical structure of networks between energy and non-energy firms may or may not be unique to Japan. There remains a need for comparative studies of network evolution in the literature; with increasingly available panel data on interfirm interactions and methods for analysis of such data, comparisons with the present results should become possible in the future. The first studies applying comparable methods on different samples confirm that firms do not connect with one another like molecules according to natural laws and that their networking strategies can diverge between sectors and evolve over time (Koskinen et al., 2015; Matous \& Todo, 2015). Future studies utilizing deeper contextual information will further illuminate the conditions, the management strategies and the policies that best promote resilience and healthy economic performance. 


\section{Acknowledgments}

This study utilized firm-level data licensed to RIETI, which were collected by Tokyo Shoko Research. The authors thank Michal Fabinger, Masahisa Fujita, Masayuki Morikawa, Hiroyuki Nakata, Yasuyuki Sawada, Eric Weese, participants at the RIETI Discussion Paper seminar, and anonymous reviewers for their helpful comments. Financial support from JSPS Grant-in-Aid for Scientific Research is gratefully acknowledged.

\section{Supplementary materials}

For supplementary material for this article, please visit http://dx.doi.org/10.1017/ nws.2015.37.

\section{References}

Acemoglu, D., Ozdaglar, A., \& Tahbaz-Salehi, A. (2015). Networks, shocks, and systemic risk. NBER Working Paper, (20931), 1-36.

Albert, R., Jeong, H., \& Barabási, A.-L. (2000). Error and attack tolerance of complex networks. Nature, 406(6794), 378-382.

Amiti, M., \& Cameron, L. (2007). Economic geography and wages. Review of Economics and Statistics, 89(1), 15-29.

Anderson, J. E. (1979). A theoretical foundation for the gravity equation. The American Economic Review, 69(1), 106-116.

Antràs, P., \& Chor, D. (2013). Organizing the global value chain. Econometrica, 81(6), 21272204.

Antràs, P., Chor, D., Fally, T., \& Hillberry, R. (2012). Measuring the upstreamness of production and trade flows. American Economic Review, 102(3), 412-416.

Aoyama, H., Fujiwara, Y., Ikeda, Y., Iyetomi, H., \& Souma, W. (2010). Econophysics and companies: Statistical life and death in complex business networks. Cambridge: Cambridge University Press.

Bailey, J. P., \& Bakos, J. Y. (1997). An exploratory study of the emerging role of electronic intermediariations and policy. International Journal of Electronic Commerce, 19(5), 406-417.

Barthélemy, M. (2011). Spatial networks. Physics Reports, 499(1-3), 1-101.

Bergstrand, J. H., \& Egger, P. (2007). A knowledge-and-physical-capital model of international trade flows, foreign direct investment, and multinational enterprises. Journal of International Economics, 73(2), 278-308.

Cairncross, F. (2001). The death of distance 2.0. New York and London: Texere.

Canals, C., Gabaix, X., Vilarrubia, J. M., \& Weinstein, D. E. (2007). Trade patterns, trade balances and idiosyncratic shocks. Banco de España Research Paper No. WP-0721.

Caplow, T., \& Forman, R. (1950). Neighborhood interaction in a homogeneous community. American Sociological Review, 15(3), 357-366.

Carrasco, J. A., Hogan, B., Wellman, B., \& Miller, E. J. (2008a). Agency in social activity interactions: The role of social networks in time and space. Tijdschrift voor Economische en Sociale Geografie, 99(5), 562-583.

Carrasco, J. A., \& Miller, E. J. (2006). Exploring the propensity to perform social activities: A social network approach. Transportation, 33(5), 463-480.

Carrasco, J.-A., \& Miller, E. J. (2008). The social dimension in action: A multilevel, personal networks model of social activity frequency between individuals. Transportation Research Part A, 43(1), 90-104. 
Carrasco, J. A., Miller, E. J., \& Wellman, B. (2008b). How far and with whom do people socialize? Empirical evidence about distance between social network members. Transportation Research Record: Journal of the Transportation Research Board, 2076, 114 122.

Carvalho, V. M., Nirei, M., \& Saito, Y. U. (2014). Supply chain disruptions: Evidence from the great east Japan earthquake. RIETI Discussion Paper Series, (14-E-035), 1-14.

Center For Spatial Information Science. University of Tokyo http://newspat.csis.utokyo.ac.jp/geocode/.

Coleman, J. S. (1988). Social capital in the creation of human capital. American Journal of Sociology, 94 (ArticleType: research-article / Issue Title: Supplement: Organizations and Institutions: Sociological and Economic Approaches to the Analysis of Social Structure / Full publication date: 1988 / Copyright (c) 1988 The University of Chicago Press), S95-S120.

Cooper, M. C., Lambert, D. M., \& Pagh, J. D. (1997). Supply chain management: More than a new name for logistics. International Journal of Logistics Management, 8(1), 1-14.

Costinot, A., Vogel, J., \& Wang, S. (2013). An elementary theory of global supply chains. The Review of Economic Studies, 80(1), 109-144.

Daraganova, G., Pattison, P., Koskinen, J., Mitchell, B., Bill, A., Watts, M., \& Baum, S. (2012). Networks and geography: Modelling community network structures as the outcome of both spatial and network processes. Social Networks, 34(1), 6-17.

Dixit, A. K., \& Grossman, G. M. (1982). Trade and protection with multistage production. The Review of Economic Studies, 49(4), 583-594.

Duranton, G., \& Overman, H. G. (2005). Testing for localization using micro-geographic data. The Review of Economic Studies, 72(4), 1077-1106.

Duranton, G., \& Puga, D. (2004). Chapter 48 micro-foundations of urban agglomeration economies. In J. V. Henderson, \& T. Jacques-François (Eds.), Handbook of regional and urban economics. vol. 4, (pp. 2063-2117). New York, NY: Elsevier.

Ellram, L. M., \& Cooper, M. C. (1990). Supply chain management, partnership, and the shipper - third party relationship. International Journal of Logistics Management, 1(2), $1-10$.

Friedman, T. L. (2005). The world is flat: A brief history of the twenty-first century. New York: Farrar, Straus and Giroux.

Fujita, M., \& Thisse, J.-F. (2013). Economics of agglomeration: Cities, industrial location, and globalization. Cambridge: Cambridge University Press.

Gabaix, X. (2011). The granular origins of aggregate fluctuations. Econometrica, 79(3), 733772.

Gonzalez, M. C., Hidalgo, C. A., \& Barabasi, A.-L. (2008). Understanding individual human mobility patterns. Nature, 453(7196), 779-782.

Granovetter, M. (1985). Economic action and social structure: The problem of embeddedness. American Journal of Sociology, 91(3), 481-510.

Granovetter, M. (2005). Business groups and social organization. In N. J. Smelser \& R. Swedberg (Eds.), The handbook of economic sociology. Princeton: Princeton University Press.

Greenbaum, S. D., \& Greenbaum, P. E. (1985). The ecology of social networks in four urban neighborhoods. Social Networks, 7(1), 47-76.

Harel, D., \& Koren, Y. (2002). A fast multi-scale method for drawing large graphs. Journal of Graph Algorithms and Applications, 6(3), 179-202.

Hipp, J. R., \& Perrin, A. J. (2009). The simoultaneous effects of social distance and physical distance on the formation of neighborhood ties. City \& Community, 8(1), 5-25.

Hoover, E. M., Jr. (1937). Spatial price discrimination. The Review of Economic Studies, 4(3), 182-191.

Kim, K. A., \& Nofsinger, J. R. (2005). Institutional herding, business groups, and economic regimes: Evidence from Japan. The Journal of Business, 78(1), 213-242. 
Koskinen, J., Caimo, A., \& Lomi, A. (2015). Simultaneous modeling of initial conditions and time heterogeneity in dynamic networks: An application to foreign direct investments. Network Science, 3(1), 58-77.

Koskinen, J., \& Lomi, A. (2013). The local structure of globalisation - the network dynamics of foreign direct investments in the international electricity industry. Journal of Statistical Physics, 151(3-4), 523-548.

Lincoln, J., \& Gerlach, M. (2004). Japan's network economy: Structure, persistence, and change. Cambridge: Cambridge University Press.

Lospinoso, J. A., \& Snijders, T. A. B. (2011). Goodness of fit for social network dynamics. Sunbelt $X X X I$. St. Pete's beach, Florida.

Marshall, A. (1920). Principles of economics. London: Macmillan and Co, Ltd. Library of Economics and Liberty [Online]. Retrieved from http://www.econlib.org/library/ Marshall/marP.html

Matous, P., \& Todo, Y. (2015). Dissolve the keiretsu or die: A longitudinal study of disintermediation in the Japanese automobile industry. RIETI Discussion Paper Series, (15-E-039), 1-24.

Matous, P., Todo, Y., \& Mojo, D. (2013). Boots are made for walking: Interactions across physical and social space in infrastructure-poor regions. Journal of Transport Geography, 31(0), 226-235.

Mentzer, J. T., DeWitt, W., Keebler, J. S., Min, S., Nix, N. W., Smith, C. D., \& Zacharia, Z. G. (2001). Defining supply chain management. Journal of Business Logistics, 22(2), 1-25.

Motohashi, K. (2008). Growing R\&D collaboration of Japanese firms and policy implications for reforming the national innovation system. Asia Pacific Business Review, 14(3), 339-361.

Nakajima, K., Saito, Y., \& Uesugi, I. (2012). Localization of interfirm transaction relationships and industry agglomeration. RIETI Discussion Paper Series. Tokyo: The Research Institute of Economy, Trade and Industry.

Nakajima, K., \& Todo, Y. (2013). Determinants of transaction partners' quality: Evidence from the great east Japan earthquake. RIETI Discussion Paper Series, (13-J-024), 1-15.

Onnela, J.-P., Arbesman, S., González, M. C., Barabási, A.-L., \& Christakis, N. A. (2011). Geographic constraints on social network groups. PLoS ONE, 6(4), e16939.

Preciado, P., Snijders, T. A. B., Burk, W. J., Stattin, H., \& Kerr, M. (2012). Does proximity matter? Distance dependence of adolescent friendships. Social Networks, 34(1), 18-31.

Puga, D. (2010). The magnitude and causes of agglomeration economies. Journal of Regional Science, 50(1), 203-219.

Ripley, R., Snijders, T. A. B., \& Preciado, P. (2012). Manual for SIENA version 4. Oxford: University of Oxford.

Robins, G. (2013). Network governance of environmental systems: Structure, culture and effectiveness, day-to-day and in disasters. Paper presented at Xi'an INSNA conference. Xi'an.

Rosenthal, S. S., \& Strange, W. C. (2001). The determinants of agglomeration. Journal of Urban Economics, 50(2), 191-229.

Sanyal, K. K. (1983). Vertical specialization in a ricardian model with a continuum of stages of production. Economica, 50(197), 71-78.

Sato, H., Hirata, N., Koketsu, K., Okaya, D., Abe, S., Kobayashi, R., ... Harder, S. (2005). Earthquake source fault beneath Tokyo. Science, 309(5733), 462-464.

Sato, Y. (2012). The impact of the great east Japan earthquake on companies in the nonaffected areas: Structure of the inter-company network of supply chains and its implication. RIETI Discussion Paper Series, 12-J-020.

Schaefer, D. R. (2012). Youth co-offending networks: An investigation of social and spatial effects. Social Networks, 34(1), 141-149.

Snijders, T. A. B. (2001). The statistical evaluation of social network dynamics. Sociological Methodology, 31(1), 361-395. 
Snijders, T. A. B., Lomi, A., \& Torló, V. J. (2013). A model for the multiplex dynamics of twomode and one-mode networks, with an application to employment preference, friendship, and advice. Social Networks, 35(2), 265-276.

Snijders, T. A. B., van de Bunt, G. G., \& Steglich, C. E. G. (2010). Introduction to stochastic actor-based models for network dynamics. Social Networks, 32(1), 44-60.

Song, C., Qu, Z., Blumm, N., \& Barabási, A.-L. (2010). Limits of predictability in human mobility. Science, 327(5968), 1018-1021.

Steglich, C., Snijders, T. A. B., \& Pearson, M. (2010). Dynamic networks and behavior: Separating selection from influence. Sociological Methodology, 40(1), 329-393.

Tallontire, A. (2000). Partnerships in fair trade: Reflections from a case study of Cafe 'direct. Development in Practice, 10(2), 166-177.

Todo, Y., Nakajima, K., \& Matous, P. (2014). How do supply chain networks affect the resilience of firms to natural disasters? Evidence from the great east Japan earthquake. Journal of Regional Science, 55(2), 209-229.

Tokui, J., Arai, N., Kawasaki, K., Miyagawa, T., Fukao, K., Arai, S., ... Noguchi, N. (2012). Higashi-nihon dai-shinsai no keizaiteki eikyo: kako no saigai tono hikaku, sapurai chen no sundan koka, denryoku seiyaku no eikyo (in Japanese). RIETI Policy Discussion Paper, No. 12-P-004.

Tokyo Shoko Research (2010). Kigyou Soukan Jouhou Tokyo Shoko Research. Tokyo Shoko Research, Tokyo.

van der Berg, P., Arentze, T., \& Timmermans, H. (2010). A multilevel path analysis of contact frequency between social network members. Geographical Systems, 14(2), 1-17.

Wellman, B., \& Tindall, D. B. (1992). How telephone networks connect social networks. Progress in Communication Research, 13, 63-94.

Wilkerson, G. K., Ramin, \& Schmid, S. (2013). Urban mobility scaling: lessons from 'Little Data'. ARXIV arXiv:1401.0207, 6.

Wilson, A. G. (1967). A statistical theory of spatial distribution models. Transportation Research, 1(3), 253-269.

Woo-Sung, J., Fengzhong, W., \& Stanley, H. E. (2008). Gravity model in the Korean highway. EPL (Europhysics Letters), 81(4), 48005. 